\title{
IMPLEMENTASI DATA MINING UNTUK MENENTUKAN KELAYAKAN PEMBERIAN KREDIT DENGAN MENGGUNAKAN ALGORITMA K-NEAREST NEIGHBORS (K-NN)
}

\author{
Tupan Tri Muryono", Irwansyah ${ }^{2 *}$ \\ Program Studi Sistem Informasi ${ }^{1}$, Teknik Informatika ${ }^{2}$, STMIK Widuri Jakarta, Indonesia \\ E-mail: ${ }^{1}$ tupan_tm@yahoo.com, ${ }^{2}$ irwansyahsf07@gmail.com
}

Submission date: 2020-06-04

Accepted date: 2020-06-09

\begin{abstract}
The banking world in terms of lending to customers is routine activities that are at high risk. In its execution, the problematic credit or bad credit is often due to the lack of careful credit analysis in the process of granting credit, as well as from poor customers. The purpose of this study is to implement data mining to assist in conducting credit analysis process in order to produce the right information whether the customer who will apply for the credit is worthy or not to be able to see the potential payment by the customer. The attributes used in this study consist of 11 attributes i.e. marital status, number of liabilities, age, last education, occupation, monthly income, home ownership, warranties, loan amount, length of loan and description as a result attribute. The methods of data collection used are observation, interviews, and documentation. The method used in this study is $K$-Nearest Neighbor $(K-N N)$. From the results of evaluation and validation using the $K-5$ fold that has been done using the RapidMiner tools obtained the highest accuracy results from the K-Nearest Neighbor $(K-N N)$ method of $93.33 \%$ in the 5th test.
\end{abstract}

Keywords: Kredit, Data Mining, K-Nearest Neighbor

\begin{abstract}
ABSTRAK
Dunia perbankan dalam hal pemberian kredit kepada nasabah adalah kegiatan rutin yang mempunyai resiko tinggi. Dalam pelaksanaannya, kredit yang bermasalah atau kredit macet sering terjadi akibat analisis kredit kurang cermat dalam proses pemberian kredit, maupun dari nasabah yang tidak baik. Tujuan dalam penelitian ini ialah menerapkan data mining untuk dapat membantu melakukan proses analisis kredit agar dapat menghasilkan informasi yang tepat apakah nasabah yang akan mengajukan kreditnya layak atau tidaknya sehingga dapat melihat potensi pembayaran kredit yang dilakukan nasabah. Atribut yang digunakan dalam penelitian ini terdiri dari 11 atribut yaitu status perkawinan, jumlah tanggungan, usia, pendidikan terakhir, pekerjaan, penghasilan perbulan, kepemilikan rumah, jaminan, jumlah pinjaman, lama pinjaman dan keterangan sebagai atribut hasil. Metode pungumpulan data yang digunakan ialah observasi, wawancara, dan dokumentasi. Metode yang digunakan dalam penelitian ini adalah $K$-Nearest Neighbor (K-NN). Dari hasil evaluasi dan validasi menggunakan k-5 fold yang telah dilakukan menggunakan tools RapidMiner diperoleh hasil akurasi tertinggi dari Metode K-Nearest Neighbor (K-NN) sebesar $93.33 \%$ pada pengujian ke 5 .
\end{abstract}

Kata Kunci: Kredit, Data Mining, K-Nearest Neighbor

\section{PENDAHULUAN}

Dunia perbankan dalam hal pemberian kredit kepada nasabah adalah kegiatan rutin yang mempunyai resiko tinggi. Dalam pelaksanaannya, kredit yang bermasalah atau kredit macet sering terjadi akibat analisis kredit kurang cermat dalam proses pemberian kredit, maupun dari nasabah yang tidak baik.

Kredit macet atau kredit bermasalah merupakan suatu kondisi dimana pihak peminjam tidak mampu melunasi pinjaman kepada pihak yang memberi pinjaman sesuai waktu yang telah ditentukan (Mudrajad Kuncoro dan Suhardjono, 2002).

Untuk mencegah terjadinya kredit macet, seorang analisis kredit perbankan harus mengambil keputusan tepat untuk menerima ataupun menolak pengajuan kredit. Untuk mengetahui kelayakan kredit di masa mendatang, diperlukan adanya prediksi yang akurat, salah satunya menggunakan teknik data mining. Data mining adalah suatu istilah yang digunakan untuk menguraikan penemuan pengetahuan di dalam database.

Data mining adalah proses yang menggunakan teknik statistik, matematika, kecerdasan buatan dan Machine Learning untuk 
mengekstraksi dan mengidentifikasi informasi yang bermanfaat dan pengetahuan yang terakit dari berbagai database besar (Han, J, Kamber, M, \& Pei, 2002).

Dalam kaitannya data mining memiliki beberapa teknik salah satunya adalah teknik klasifikasi. Klasifikasi adalah pemrosesan untuk menemukan sebuah model atau fungsi yang menjelaskan dan mencirikan konsep atau kelas data, untuk kepentingan tertentu. Klasifikasi memiliki beberapa Algoritma klasifikasi data mining salah satunya yaitu K-Nearest Neighbors (K-NN) (Budiyantara et al., 2020).

Tujuan dalam penelitian ini ialah menerapkan data mining untuk dapat membantu melakukan proses analisis kredit agar dapat menghasilkan informasi yang tepat apakah nasabah yang akan mengajukan kreditnya layak atau tidak sehingga dapat melihat potensi pembayaran kredit yang dilakukan nasabah.

Penelitian dari Alif Wahyu Oktaputra dan Edi Noersasongko. Dengan topik Sistem Pendukung Keputusan Kelayakan Pemberian Kredit Motor Menggunakan Metode Simple Additive Weighting Pada Perusahaan Leasing Hd Finance. Berdasarkan penelitian yang dilakukan oleh peneliti, maka dapat disimpulkan, dengan adanya sistem pendukung keputusan untuk menentukan kelayakan pemberian kredit motor pada PT HD Finance, Tbk cabang Kota Semarang akan membantu dalam memberikan rekomendasi dan pertimbangan dalam pengambilan keputusan realisasi kredit berdasarkan kriteria yang telah ditentukan oleh pihak perusahaan (Oktaputra, Alif Wahyu, Noersasongko, 2014).

Penelitian dari Tri Murti, Leon Andretti Abdillah, Muhammad Sobri. Dengan topik Sistem Penunjang Keputusan Kelayakan Pemberian Pinjaman Dengan Metode Fuzzy Tsukamoto. Hasil dari penelitian yang telah penulis lakukan pada PT Triprima Finance Palembang ialah mempermudahkan dalam memberikan laporan kepada kaposko dan branch manager, serta mempermudahkan surveyor dalam memberikan laporan hasil survey. Dan Sistem ini akan menghasilkan nilai dan keputusan untuk menentukan kelayakan pemberian pinjaman. Berdasarkan nilai total tertinggi dari pengajuan pinjaman (Murti et al., 2015).

Penelitian dari Darma Dewi dan Fiqih Satria. Dengan topik Algoritma Naive Bayes Untuk Menentukan Kelayakan Pemberian Kredit Pada Adira. Pertumbuhan jumlah kredit sepeda motor terus mengalami peningkatan. Adira menyatakan pada bulan juli 2012 mencatat rekor yakni 19.000 unit, Proses pembelian sepeda motor $70 \%$ dilakukan dengan cara kredit. Guna mengatasi masalah ketepatan prediksi dengan akurasi tinggi dan kecepatan waktu dalam pengambilan keputusan pengajuan kredit sepeda motor, mengingat banyaknya jumlah pengajuan kredit yang harus ditangani, maka dibutuhkan suatu sistem yang mampu menangani hal tersebut. Maka digunakan metode naive bayes untuk membangun sistem tersebut karena naive bayes telah mencapai akurasi $100 \%$ dalam melakukan prediksi. Aplikasi ini menghasilkan penelitian untuk nilai akurasi Naivebayes adalah 85\% (Dewi \& Satria, 2017).

Keterbaharuan dalam penelitian ini yaitu : Algoritma menggunakan K-Nearest Neighbors (KNN) dan atribut serta jumlah data yang digunakan berbeda dengan penelitian sebelumnya. Hasil dari penelitian ini diharapkan dapat membantu PT. XYZ dalam menganalisis kelayakan pemberian kredit pada nasabah sehingga dapat mencegah terjadinya kredit macet yang dilakukan oleh nasabah.

\section{METODE PENELITIAN}

\section{Metode Pengumpulan Data}

Teknik pengumpulan data merupakan langkah yang paling strategis dalam penelitian karena tujuan utama dari penelitian adalah mendapatkan data. Untuk mendapatkan data yang diperlukan (Sani, 2018). Maka digunakan metode pengumpulan data yang digunakan adalah :

1. Observasi

Observasi merupakan metode pengumpulan data dengan melakukan pengamatan dan pencatatan secara teliti dan sistematis atas gejala-gejala atau fenomena yang sedang diteliti. Penulis malakukan pengamatan langsung pada PT. XYZ untuk mengidentifikasi masalah dan mengetahui bagaimana sistem yang berjalan di lembaga tersebut.

2. Wawancara

Wawancara merupakan teknik pengumpulan data yang dilakukan melalui tatap muka dan tanya jawab langsung antara peneliti dan narasumber. Seiring perkembangan teknologi, metode wawancara dapat pula dilakukan melalui mediamedia tertentu, misalnya telepon, email, atau skype. Penulis melakukan Tanya jawab langsung kepada pihak PT. XYZ. Dari hasil wawancara ini diharapkan dapat menambah kelengkapan data yang diperoleh dari hasil pengamatan.

3. Dokumentasi

Dokumentasi adalah sebuah cara yang dilakukan untuk menyediaan dokumen-dokumen dengan menggunakan bukti yang akurat dari pencatatan sumber-sumber informasi khusus dari karangan/tulisan, wasiat, buku, undang-undang, dan sebagainya.

Pada penelitian ini pengumpulan data melalui dokumen dilakukan dengan mempelajari fakta atau data yang ada pada file dokumentasi di PT. XYZ.

\section{Metode Penelitian Yang Digunakan}

Metode yang digunakan pada penelitain ini adalah K-Nearest Neighbor (K-NN) yang 
merupakan metode klasifikasi yang mengelompokan data baru berdasarkan jarak data baru kebeberapa data tetangga (neighbor) terdekat (Budiyantara et al., 2020)

Prinsip kerja algoritma K-Nearest Neighbor adalah mencari jarak terdekat antara data yang akan di evaluasi dengan k tetangga terdekatnya dalam data pelatihan. Ada banyak cara untuk mengukur jarak kedekatan antara data baru dengan data lama, diantaranya euclidean distancedan manhattan distance yang paling sering digunakan adalah euclidean distance (Bramer, 2007), yaitu sebagai berikut:

$$
X=\sqrt{(a 1-b 1)^{2}+(a 2-b 2)^{2}+\cdots+(a n-b n)^{2}}
$$

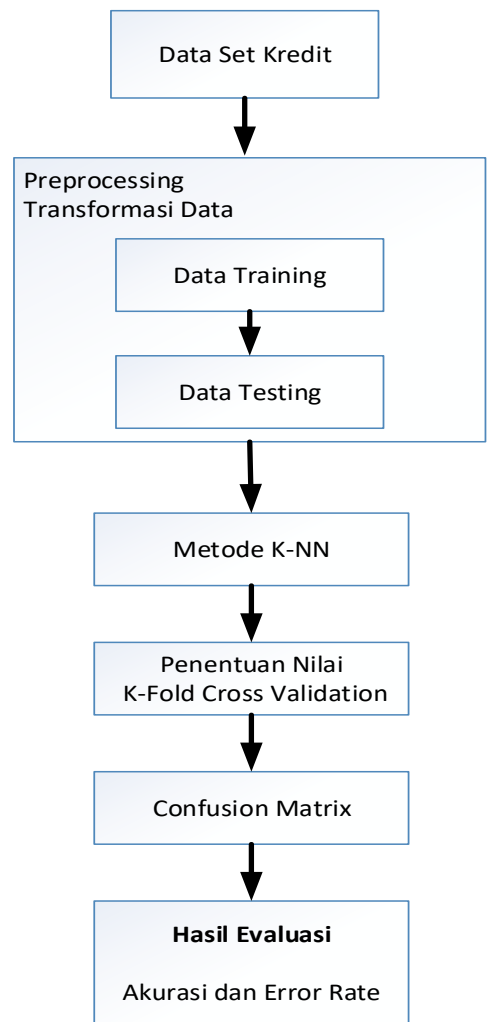

Sumber : (Tupan Tri M dan Irwansyah, 2020)

Gambar 1. Metode K-Nearest Neighbors

Pada penelitian ini data yang digunakan adalah dataset kredit yang didapatkan dari Pt. xyz sebanyak 500 data. Langkah selanjutnya dilakukan proses transformasi data set menjadi data training dan data testing. Langkah selanjutnya dataset diproses menggunakan algoritma K-NN. Langkah selanjutnya menentukan nilai k-fold dalam penelitian ini menggunakan 5 kali proses pengujian. Langkah selanjutnya untuk menguji evaluasi dan validasi algoritma digunakan confusion matrix sehingga akan didapatkan nilai akurasi dan juga error rate dari hasil eksperimen.

\section{HASIL DAN PEMBAHASAN}

\section{Pengolahan Data (Data Preparation)}

Pada tahapan ini dilakukan penyiapan data awal, pemilihan atribut atau variabal yang akan dianalisis, validasi variabel yang ada serta persiapan transformasi data. Adapun hal-hal yang dihasilkan pada fase persiapan data ini adalah :

Dilakukan persiapan data training sebanyak 350 data dan data testing sebanyak 150 data. Atribut yang digunakan terdiri dari 11 atribut yaitu : Status perkawinan, jumlah tanggungan, usia, pendidikan terakhir, pekerjaan, penghasilan perbulan, kepemilikan rumah, jaminan, jumlah pinjaman, lama pinjaman dan keterangan sebagai atribut hasil.

Berikut ini data atribut yang akan digunakan pada penelitian ini dapat kita lihat pada tabel 1 sebagai berikut :

Tabel 1. Atribut dan Nilai Dataset

\begin{tabular}{|c|c|c|}
\hline No & $\begin{array}{c}\text { Nama } \\
\text { Atribut }\end{array}$ & Nilai \\
\hline 1 & $\begin{array}{l}\text { Status } \\
\text { Perkawinan }\end{array}$ & $\begin{array}{l}\text { - Belum Menikah } \\
\text { - Sudah Menikah } \\
\text { - Janda/ Duda }\end{array}$ \\
\hline 2 & $\begin{array}{l}\text { Jumlah } \\
\text { Tanggungan }\end{array}$ & $\begin{array}{l}\text { - } \text { Tidak Ada } \\
\text { - } 1 \text { orang } \\
\text { - } 2-3 \text { orang } \\
->3 \text { orang }\end{array}$ \\
\hline 3 & Usia & $\begin{array}{l}-20-55 \\
-55-60 \\
\end{array}$ \\
\hline 4 & $\begin{array}{l}\text { Pendidikan } \\
\text { Terakhir }\end{array}$ & $\begin{array}{l}\text { - SD } \\
\text { - SLTP } \\
\text { - SLTA } \\
\text { - Diploma } \\
\text { - S1 } \\
->\text { S1 }\end{array}$ \\
\hline 5 & Pekerjaan & $\begin{array}{l}\text { - Karyawan Swasta } \\
\text { - Pedagang } \\
\text { - PNS } \\
\text { - TNI/Polri } \\
\text { - Dosen } \\
\end{array}$ \\
\hline 6 & $\begin{array}{l}\text { Penghasilan } \\
\text { Perbulan }\end{array}$ & $\begin{array}{ll}- & 1.000 .000-2.000 .000 \\
- & 2.000 .000-3.000 .000 \\
- & 3.000 .000-4.0000 .000 \\
- & >4.000 .000\end{array}$ \\
\hline 7 & $\begin{array}{l}\text { Kepemilikan } \\
\text { Rumah }\end{array}$ & $\begin{array}{ll}- & \text { Milik Sendiri } \\
- & \text { Sewa }\end{array}$ \\
\hline 8 & Jaminan & $\begin{array}{ll}- & \text { Sertifikat Tanah } \\
- & \text { Sertifikat Rumah } \\
- & \text { SK PNS/SK TNI-Polri } \\
- & \text { BPKB Kendraan Bermotor }\end{array}$ \\
\hline 9 & $\begin{array}{l}\text { Jumlah } \\
\text { Pinjaman }\end{array}$ & $\begin{array}{ll}- & 5.000 .000-15.000 .000 \\
- & 16.000 .000-30.000 .000 \\
- & 31.000 .000-50.000 .000 \\
- & 51.000 .000-100.000 .000 \\
- & >100.000 .000\end{array}$ \\
\hline 10 & $\begin{array}{l}\text { Lama } \\
\text { Pinjaman } \\
\text { (Bulan) }\end{array}$ & $\begin{array}{ll}- & 0-12 \text { Bulan } \\
- & 13-24 \text { Bulan } \\
- & 25-36 \text { Bulan } \\
- & 37-48 \text { Bulan } \\
- & >48 \text { Bulan }\end{array}$ \\
\hline 11 & Keterangan & $\begin{array}{ll}- & \text { Lancar } \\
\text { - } & \text { Macet }\end{array}$ \\
\hline
\end{tabular}

Sumber : (Tupan Tri M dan Irwansyah, 2020) 


\section{Pengelompokkan Data}

Tabel 2. Contoh Sampel Data Testing

\begin{tabular}{|c|c|c|c|c|c|c|c|c|c|c|}
\hline $\begin{array}{c}\text { Status } \\
\text { Pernikahan }\end{array}$ & $\begin{array}{c}\text { Jumlah } \\
\text { Tanggungan }\end{array}$ & Usia & $\begin{array}{c}\text { Pendidikan } \\
\text { Terakhir }\end{array}$ & Pekerjaan & $\begin{array}{c}\text { Penghasilan } \\
\text { Perbulan }\end{array}$ & $\begin{array}{c}\text { Kepemilikan } \\
\text { Rumah }\end{array}$ & Jaminan & $\begin{array}{c}\text { Jumlah } \\
\text { Pinjaman }\end{array}$ & $\begin{array}{c}\text { Lama } \\
\text { Pinjaman } \\
\text { (bulan) }\end{array}$ & Ket \\
\hline $\begin{array}{c}\text { Belum } \\
\text { Menikah }\end{array}$ & 0 & 22 & S1 & Polri & 5.520 .500 & Milik sendiri & SK Polri & 30.000 .000 & 24 & Lancar \\
\hline $\begin{array}{c}\text { Belum } \\
\text { Menikah }\end{array}$ & 0 & 21 & D3 & Swasta & 2.211 .400 & Sewa & $\begin{array}{l}\text { BPKB } \\
\text { Motor }\end{array}$ & 15.000 .000 & 12 & Macet \\
\hline $\begin{array}{l}\text { Belum } \\
\text { Menikah }\end{array}$ & 0 & 25 & D3 & Swasta & 2.613 .500 & Milik sendiri & $\begin{array}{l}\text { BPKB } \\
\text { Motor }\end{array}$ & 20.000 .000 & 24 & Lancar \\
\hline Menikah & 2 & 45 & D3 & PNS & 3.389 .900 & Milik sendiri & SK PNS & 10.000 .000 & 12 & Lancar \\
\hline $\begin{array}{c}\text { Belum } \\
\text { Menikah }\end{array}$ & 0 & 22 & S1 & PNS & 3.537 .100 & Milik sendiri & $\begin{array}{l}\text { BPKB } \\
\text { Motor }\end{array}$ & 8.000 .000 & 12 & Lancar \\
\hline
\end{tabular}

Sumber : (Tupan Tri M dan Irwansyah, 2020)

Pada tabel 2. diatas merupakan contoh 10 data yang digunakan untuk data latih atau data traning. Pada penelitian ini data training yang digunakan sebanyak 350 data nasabah.

\section{Evaluasi dan Validasi}

Evaluasi Model Menggunakan Tools RapidMiner. Desain model yang akan digunakan dapat kita lihat pada gambar 2 dan 3 sebagai berikut:

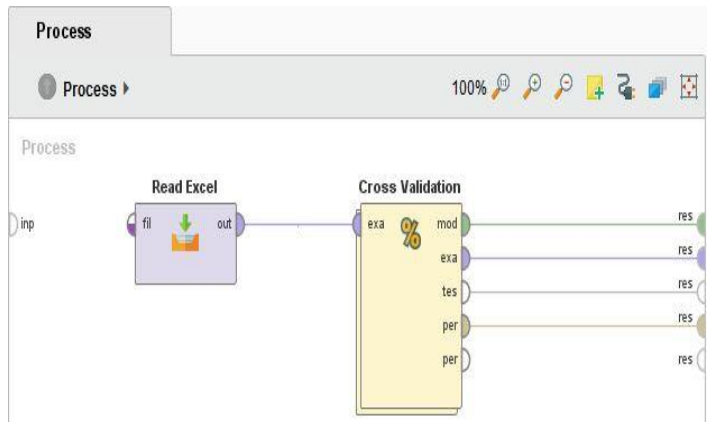

Sumber : (Tupan Tri M dan Irwansyah, 2020)

Gambar 2. Proses Desain dan Import Data Dengan Tools RapidMiner

1. Read Excel : Operator ini dapat digunakan untuk memuat data dari spreadsheet Microsoft Excel.

2. Cross Validation: Operator yang bersarang. Ini memiliki dua subproses: subproses pelatihan dan subproses pengujian. Subproses pelatihan digunakan untuk melatih model. Model yang terlatih kemudian diterapkan dalam subproses pengujian. Kinerja model diukur selama fase Pengujian.

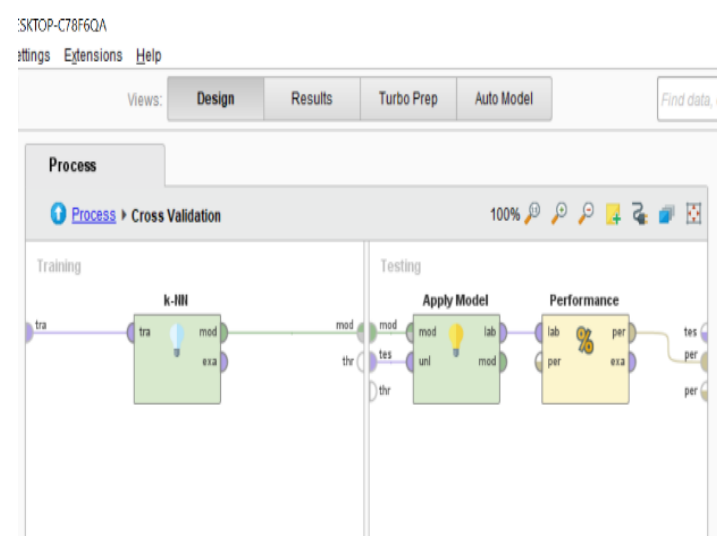

Sumber : (Tupan Tri M dan Irwansyah, 2020) Gambar 3. Desain Cross Validation Menggunakan Algoritma K-NN

3. K-Nearest Neighbors : Metode data mining yang digunakan dalam penelitian ini.

4. Apply Model : Operator yang digunakan untuk penghubung metode $k$-Nearest Neighbor ke performance.

5. Performance : Operator yang digunakan untuk mengukur performance akurasi dari model.

Evaluasi model menggunakan Cross Validation dan Confusion Matrix

\section{Pengujian K-2 Cross Validation}

Penelitian ini melakukan proses evaluasi model dengan menggunakan k-2 cross validation. Dapat kita lihat pada gambar 4 sebagai berikut : 


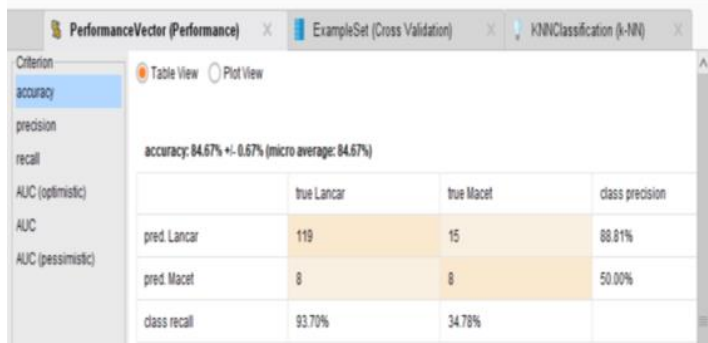

Sumber : (Tupan Tri M dan Irwansyah, 2020)

Gambar 4. Pengujian K-2 Cross Validation

Dari proses evaluasi model K-Nearest Neighbors dan proses validasi terbentuk hasil matrix Accuracy sebesar $84.67 \%$.

Dibawah ini merupakan perhitungan Akurasi menggunakan Confusion Matrix dari gambar 5 diatas.

$$
\begin{aligned}
\text { Accuracy }= & \frac{T P+T N}{T P+T N+F P+F N}+\frac{119+8}{119+8+15+8}+\frac{127}{150}= \\
& 0,8466=84,67 \% \ldots \ldots \ldots \ldots \ldots \ldots \ldots \ldots \ldots \ldots \ldots \ldots \ldots \ldots \ldots \ldots \ldots \ldots \ldots \ldots \ldots
\end{aligned}
$$

\section{Pengujian K-3 Cross Validation}

Penelitian ini melakukan proses evaluasi model dengan menggunakan k-3 cross validation. Dapat kita lihat pada gambar 5 sebagai berikut :

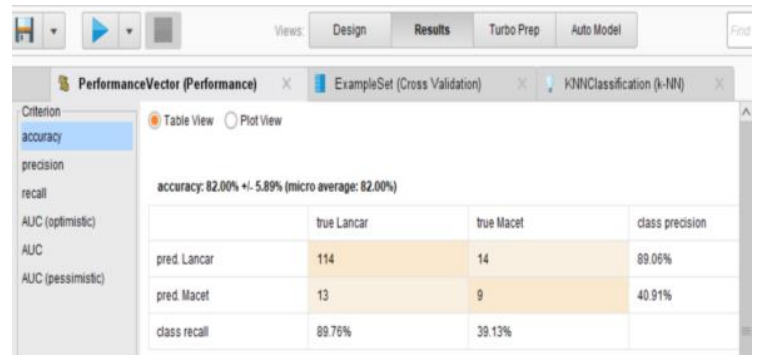

Sumber : (Tupan Tri M dan Irwansyah, 2020)

Gambar 5. Pengujian K-3 Cross Validation

Dari proses evaluasi model K-Nearest Neighbors dan proses validasi terbentuk hasil matrix Accuracy sebesar $82.00 \%$.

Dibawah ini merupakan perhitungan Akurasi menggunakan Confusion Matrix dari gambar 5 diatas.

$$
\begin{array}{r}
\text { Accuracy }=\frac{T P+T N}{T P+T N+F P+F N}+\frac{114+9}{114+9+13+14}+\frac{123}{150}= \\
0,82=82,00 \% \ldots \ldots \ldots \ldots \ldots \ldots \ldots \ldots \ldots \ldots \ldots \ldots \ldots \ldots \ldots \ldots \ldots \ldots \ldots \ldots \ldots \ldots \ldots \ldots \ldots \ldots
\end{array}
$$

\section{Pengujian K-4 Cross Validation}

Penelitian ini melakukan proses evaluasi model dengan menggunakan k-4 cross validation. Dapat kita lihat pada gambar 6 sebagai berikut :

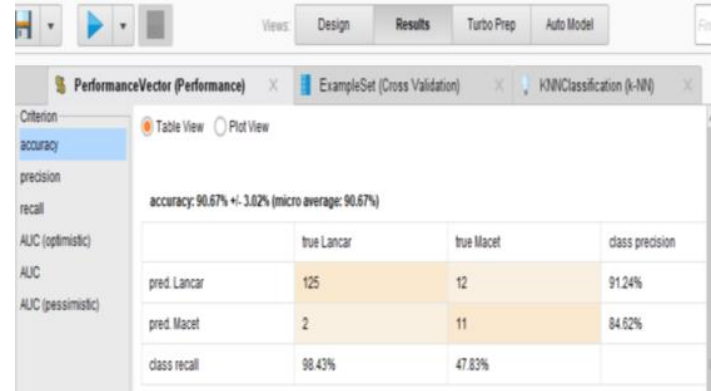

Sumber : (Tupan Tri M dan Irwansyah, 2020)

Gambar 6. Pengujian K-4 Cross Validation

Dari proses evaluasi model K-Nearest Neighbors dan proses validasi terbentuk hasil matrix Accuracy sebesar $90.67 \%$.

Dibawah ini merupakan perhitungan Akurasi menggunakan Confusion Matrix dari gambar 5 diatas.

$$
\begin{array}{r}
\text { Accuracy }=\frac{T P+T N}{T P+T N+F P+F N}+\frac{125+11}{125+11+2+12}+\frac{136}{150}= \\
0,9066=90,67 \% \ldots \ldots \ldots \ldots \ldots \ldots \ldots \ldots \ldots \ldots \ldots \ldots \ldots \ldots \ldots \ldots \ldots \ldots \ldots \ldots \ldots
\end{array}
$$

\section{Pengujian K-5 Cross Validation}

Penelitian ini melakukan proses evaluasi model dengan menggunakan k-5 cross validation. Dapat kita lihat pada gambar 7 sebagai berikut :

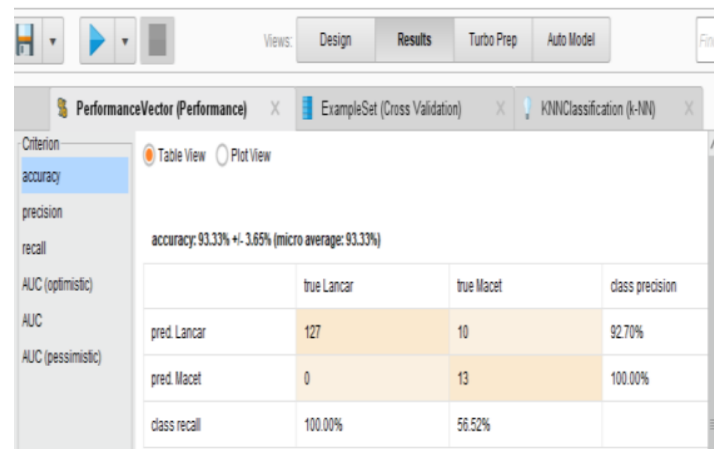

Sumber : (Tupan Tri M dan Irwansyah, 2020)

Gambar 7. Pengujian K-5 Cross Validation

Dari proses evaluasi model $K$-Nearest Neighbors dan proses validasi terbentuk hasil matrix Accuracy sebesar $93.33 \%$.

Dibawah ini merupakan perhitungan Akurasi menggunakan Confusion Matrix dari gambar 5 diatas.

$$
\begin{array}{r}
\text { Accuracy }=\frac{T P+T N}{T P+T N+F P+F N}+\frac{127+13}{127+13+0+10}+\frac{140}{150}= \\
0,9333=93,33 \% \ldots \ldots \ldots \ldots \ldots \ldots \ldots \ldots \ldots \ldots \ldots \ldots \ldots \ldots \ldots \ldots \ldots \ldots \ldots
\end{array}
$$




\section{Hasil Pengujian Menggunakan K-5 Cross Validation}

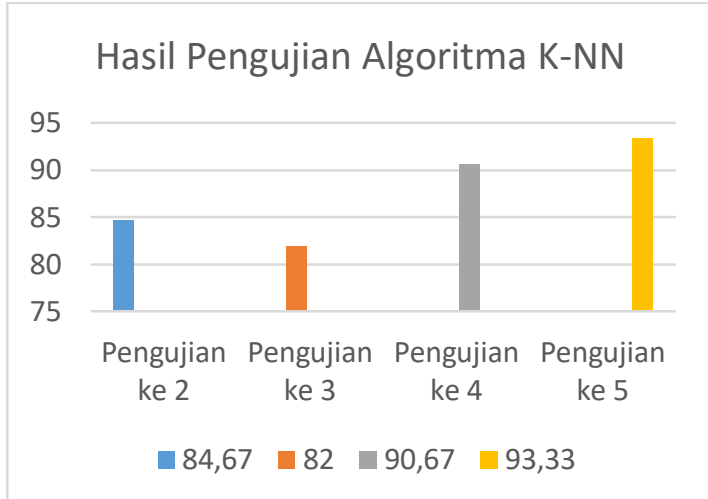

Sumber: (Tupan Tri M dan Irwansyah, 2020)

Gambar 8. Diagram Chart Pengujian Algoritma

$$
\text { K-NN }
$$

Pada diagram chart dapat kita lihat pengujian ke 2 memiliki akurasi sebesar 84,67\%, pengujian ke 3 memiliki akurasi sebesar 82\%, pengujian ke 4 memiliki akurasi sebesar 90,67\%, dan pengujian ke 5 memiliki akurasi sebesar 93,33\%, pengujian ini menggunakan teknik K-5 fold cross validation terhadap data nasabah.

\section{KESIMPULAN}

Atribut yang digunakan untuk menentukan kelayakan pemberian kredit terdiri dari 11 atribut yaitu Status perkawinan, jumlah tanggungan, usia, pendidikan terakhir, pekerjaan, penghasilan perbulan, kepemilikan rumah, jaminan, jumlah pinjaman, lama pinjaman dan keterangan sebagai atribut hasil. Dari hasil proses pengujian dengan menggunakan Algoritma K-Nearest Neighbors (K-NN) yang telah dilakukan menggunakan tools RapidMiner. Diperoleh hasil akurasi sebesar $93.33 \%$ pada pengujian ke 5 .

\section{DAFTAR PUSTAKA}

Agus Budiyantara, Irwansyah, Egi Prengki, P. A. P. (2020). Komparasi Algoritma Decision Tree, Naive Bayes Dan K-Nearest Neighbor Untuk Memprediksi Mahasiswa Lulus Tepat Waktu.

Bramer, M. (2007). Principles of Data Mining: Undergraduate Topics in Computer Science. Springer-Verlag.

Dewi, D., \& Satria, F. (2017). Algoritma Naive Bayes Untuk Menentukan Kelayakan Pemberian Kredit Pada Adira. Jurnal Sistem Informasi STMIK Pringsewu Lampung, 813 .

Han, J, Kamber, M, \& Pei, J. (2002). Data Mining: Concept and Techniques (2nd ed.). Morgan Kaufmann.

Mudrajad Kuncoro dan Suhardjono. (2002). Manajemen Perbankan: Teori dan Aplikasi (1st ed.). BPFE.

Murti, T., Abdillah, L. A., \& Sobri, M. (2015). Sistem penunjang keputusan kelayakan pemberian pinjaman dengna metode fuzzy tsukamoto. 252-256. http://arxiv.org/abs/1506.00091

Oktaputra, Alif Wahyu, Noersasongko, E. (2014). Sistem Pendukung Keputusan Kelayakan Pemberian Kredit Motor Menggunakan Metode Simple Additive Weighting Pada Perusahaan Leasing $\mathrm{Hd}$ Finance. Ilmu Komputer, Jurnal SPK Kelayakan Pemberian Kredit Motor, 1-9.

Sani, A. (2018). Penerapan Metode K-Means Clustering Pada Perusahaan. Jurnal Ilmiah Teknologi Informasi, 353, 1-7.

Tupan Tri M dan Irwansyah. (2020). Implementasi Data Mining Untuk Menentukan Kelayakan Pemberian Kredit Dengan Menggunakan Algoritma K-Nearest Neighbors (K-Nn). 